\title{
Surface seiches in Flathead Lake
}

\author{
G. Kirillin ${ }^{1,2}$, M. S. Lorang ${ }^{2}$, T. C. Lippmann ${ }^{2,3}$, C. C. Gotschalk ${ }^{2}$, and S. Schimmelpfennig ${ }^{1}$ \\ ${ }^{1}$ Department of Ecohydrology, Leibniz Institute of Freshwater Ecology and Inland Fisheries (IGB), Berlin, Germany \\ ${ }^{2}$ The University of Montana, Flathead Lake Biological Station, Polson, MT, USA \\ ${ }^{3}$ University of New Hampshire, Dept. of Earth Sciences and Center for Coastal and Ocean Mapping, NH, USA
}

Correspondence to: G. Kirilin (kirillin@igb-berlin.de)

Received: 10 October 2014 - Published in Hydrol. Earth Syst. Sci. Discuss.: 10 December 2014

Revised: 14 April 2015 - Accepted: 11 May 2015 - Published: 3 June 2015

\begin{abstract}
Standing surface waves or seiches are inherent hydrodynamic features of enclosed water bodies. Their twodimensional structure is important for estimating flood risk, coastal erosion, and bottom sediment transport, and for understanding shoreline habitats and lake ecology in general. In this work, we present analysis of two-dimensional seiche characteristics in Flathead Lake, Montana, USA, a large intermountain lake known to have high seiche amplitudes. To examine spatial characteristics of different seiche modes, we used the original procedure of determining the seiche frequencies from the primitive equation model output with subsequent derivation of the spatial seiche structure at fixed frequencies akin to the tidal harmonic analysis. The proposed procedure revealed specific seiche oscillation features in Flathead Lake, including maximum surface level amplitudes of the first fundamental mode in straights around the largest island; several higher modes appearing locally in the vicinity of the river inflow; the "Helmholtz" open harbor mode, with the period approximately twice that of the longest seiche mode, generated by a large shallow bay connected to the main lake basin; and several rotating seiche modes potentially affecting the lake-wide circulation. We discuss lake management problems related to the spatial seiche distribution, such as shoreline erosion, floods, and transport of sediments and invasive species in Flathead Lake.
\end{abstract}

\section{Introduction}

Since Forel (1895); see also Forel and von Zeppelin (1893) first described free-surface oscillations in Alpine lakes and coined the term "seiches", standing basin-scale waves have been recognized as distinguishing features of lake hydrody- namics. Seiches exist in any (semi) enclosed basin, where long surface waves reflecting at opposite shores interfere to produce a standing wave. The longest possible seiche (the first "fundamental" mode) has the wavelength $\lambda$ that is twice the distance between the shores, $L$. The wavelengths of other possible modes decrease by even fractions of the distance between shores. Therefore, for the majority of possible modes, seiche waves are very long compared to the lake depth. This characteristic allows application of shallow water linear wave theory to the analysis of seiche motion (see, e.g., Turner, 1973). The dispersion relation for the one-dimensional long linear waves yields the well-known Merian formula (von der Mühll, 1886)

$\omega=c \lambda^{-1}=n c(2 L)^{-1}$,

where $\omega=1 / T^{-1}$ is the oscillation frequency, $T$ is the period of oscillation, $c=(g H)^{1 / 2}$ is the phase speed of the long wave in a basin with mean depth $H$, and $n=1,2,3 \ldots$ is the seiche mode. Equation (1) corresponds to a planar wave propagating in one lateral dimension, and performs well for lower modes $(\operatorname{small} n)$ in basins of quasi-rectangular or elongated canal-like shape (Defant, 1961). In lakes of more complex shape, the lateral structure of modes is essentially twodimensional in the horizontal plane (Rueda and Schladow, 2002; Kirillin et al., 2008). Hutter et al. (2011) presented an overview of the seiche problem with mathematical background, a bibliography, and examples from different lakes. Interference of multiple modes in basins with a highly indented shoreline, as well as strong variations in depth, may produce seiches with frequencies deviating from those predicted by Eq. (1) (Rueda and Schladow, 2002; Hutter et al., 1982), may strongly increase amplitudes of nearshore water level oscillations (Hollan et al., 1980; Rudnev et al., 
1995), or give rise to local rotating modes (Rao and Schwab, 1976). These seiche effects are especially important in large lakes, gulfs, and seas, where a local increase in seiche amplitudes can threaten populated areas with flooding (Hollan et al., 1980; Kulikov and Medvedev, 2013). Coastal erosion, nearshore wetland habitat structure, and sediment transport are also seiche-related issues relevant to water and coastal management. Determining the two-dimensional seiche structure from observations requires large amounts data on water level and current velocity from multiple sites along the shoreline and can have high uncertainty due to contamination of data by frequency aliasing or non-seiche oscillations (Mortimer and Fee, 1976). Numerical modeling is an effective alternative to observational approaches. Among modeling studies on the two-dimensional structure of seiches in large basins with complex morphometry, the "normal modes" approach has been widely used, based on replacement of the system of equations for water motion with their equivalents for harmonic functions of space and time. This approach reduces the numerical problem to a discrete set of eigenvalue solutions, each corresponding to a certain seiche mode (Csanady, 1967; Platzman, 1972; Rao and Schwab, 1976). A more straightforward approach based on isolation of seiche motions from the results of direct hydrodynamic simulation with primitive equations of motion has a certain advantage owing to the recent improvements in computational techniques (Suursaar et al., 2002; Jönsson et al., 2008). Since circulation modeling with primitive equation models has become routine during the last decades, many model codes have become freely available and their application is not overly time-consuming. In addition, existing outputs from circulation models, applied previously to different bays, lakes, or estuaries, may be later reanalyzed using appropriate methods for estimation of seiche characteristics. In this study we present an analysis of the modal structure of seiches in Flathead Lake (described below). Instead of applying eigenvalue solutions for a priori periodic velocities and surface elevations, we solved a "backward" problem by applying harmonic analysis to the output of a primitive equations model, and deriving a discrete set of seiche eigenfrequencies from a "synthetic" spectrum for all grid points of the calculation domain. The method is an effective way of obtaining detailed information on the possible spatial structure of free-surface oscillations in Flathead Lake. We discuss the lake-specific features of these oscillations and mechanisms of their generation, and their potential importance for predicting floods, coastal erosion, and occurrence and structure of nearshore wetland habitats around the lake.

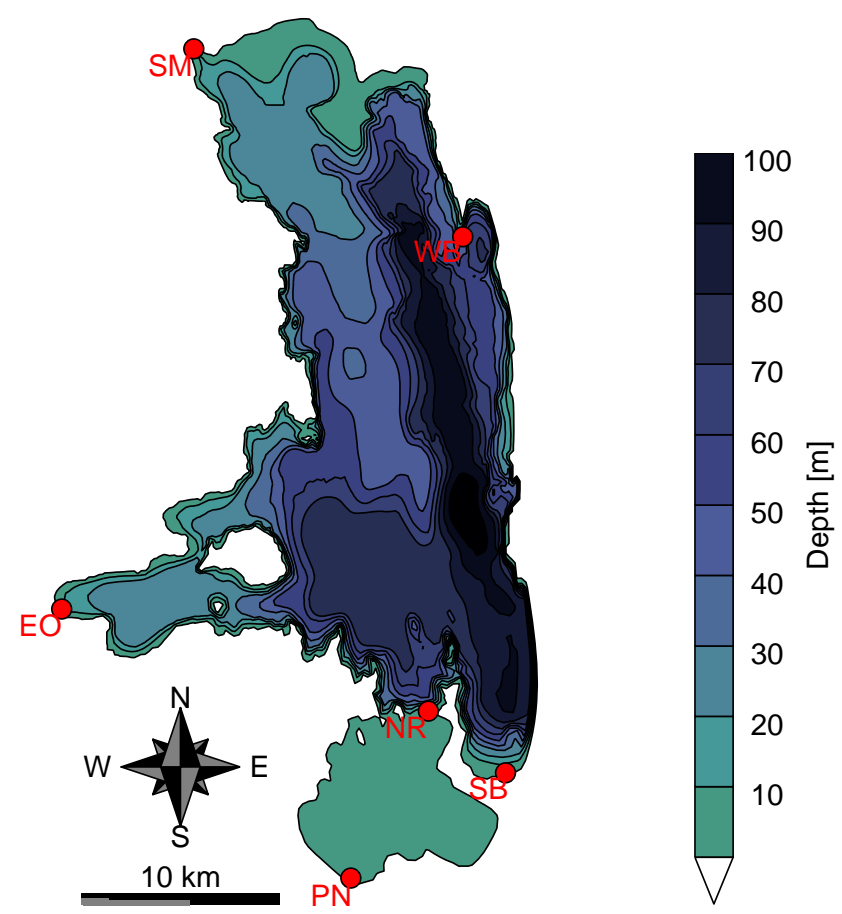

Figure 1. Flathead Lake: bathymetry map and location of pressure and water level measurement sites (red circles), referred to in the text.

\section{Study site and methods}

\subsection{Flathead Lake}

\subsubsection{Lake origin and morphology}

Flathead Lake is a natural glacial lake located in the Rocky Mountains of the western US $\left(47^{\circ} 52^{\prime} \mathrm{N}, 114^{\circ} 07^{\prime} \mathrm{W}\right.$ approximate lake center). It is the largest freshwater lake in the western contiguous USA, extending $45 \mathrm{~km}$ by $24 \mathrm{~km}$ and with $496 \mathrm{~km}^{2}$ surface area (Fig. 1). Its origin is attributed to the final retreat of the Flathead glacial lobe, a southern extension of the continental Cordilleran ice sheet, which resulted in melt waters filling the southern end of a northsouth-oriented fault-block valley (Lorang et al., 1993b). The process of glacial advance and retreat created Polson Bay (PN in Fig. 1), a shallow (approximately $8 \mathrm{~m}$ deep), circular bay at the southern outlet which runs through the terminal moraine. Polson Bay is connected to the main deep body of the lake through a relatively narrow bedrock island-filled gap (The Narrows, NR in Fig. 1). A branch of the Flathead glacial lobe also created Big Arm Bay, a narrow mediumdeep ( $25 \mathrm{~m}$ average depth) east-west-oriented bay that is bounded by Wildhorse Island, the main island in the lake. The main body of the lake is dominated by a north-southoriented $100 \mathrm{~m}$ deep trench, bordered by a wider and more shallow shelf with a mean depth of $50 \mathrm{~m}$ (Fig. 1). The combination of plate tectonics and glacial processes (basin scour 
during advance and deposition during retreat) has resulted in a lake with a range of shoreline types, islands, bays, and bathymetric provinces. Mountain ranges on either side topographically control wind that provides the principal driving force for seiche motion in the lake. Wind-generated surface gravity waves (with periods of 1-3 s) generated in the main body of the lake maintain a sandy-silt sediment deposit in the northern half of Polson Bay (Lorang, 1984), and fine silts and clay elsewhere in the bay and most of the lake bottom. Sediments delivered by the Flathead River (which drains a $18372 \mathrm{~km}^{2}$ catchment) formed a large delta where the river enters the lake. This sand-silt delta extends several kilometers out into the lake (Fig. 1) and results in a very dissipative, low-slope, nearshore environment for the north shore (Lorang et al., 1993b). Deposition of glacial till along much of the east and west shores combined with exposed bedrock has resulted in reflective nearshore systems characterized by gravel beaches and steep inshore shelves armored by wavewashed cobble (Lorang et al., 1993b).

\subsubsection{Winds and lake level fluctuations}

Winds on Flathead Lake are thermally driven in the summer months due to differential heating and cooling on the lake surface and the adjacent mountain ranges. This thermal regime is characterized by distinct westerly thermal winds draining from mountains out on to the lake in the evening, and northerly winds driven by air masses that drain north to south in the valley early in the morning. These winds typically have a maximum speed of around $5 \mathrm{~m} \mathrm{~s}^{-1}$, with durations of 2 to $6 \mathrm{~h}$, and cover $30-50 \%$ of the lake. Passing frontal systems produce north-northwest and southsouthwest wind events in which wind speeds often reach 10$15 \mathrm{~m} \mathrm{~s}^{-1}$ with durations of 2-6h. These events often spin up and down repeatedly over periods of days and cover the entire lake. The strongest winds come out of the east and are driven by high-pressure systems that sit off to the east of the Rocky Mountains, producing local topographically channeled winds along the east shore. These east winds have been observed to reach $30-50 \mathrm{~m} \mathrm{~s}^{-1}$, and can last for hours, extending several kilometers out into the main body of the lake, being, however, limited to the central portion of the lake. During these events it can be completely calm on the west shore. Flathead Lake levels fluctuate seasonally with the spring freshet from snowmelt. However, Kerr Dam, built in 1938 and located $6 \mathrm{~km}$ below the lake outlet, now holds water in the lake for longer durations compared to predam conditions (Lorang et al., 1993a; Lorang and Stanford, 1993). Kerr Dam operations attempt to hold the lake level at a "full-pool" elevation of $881.78 \mathrm{~m}$, without exceeding that limit for approximately 4 months, then slowly lower the lake over late fall and winter months (Lorang et al., 1993a). These regulated fluctuations have concentrated wave energy at the full-pool operational lake elevation that has reconfigured the nearshore zone lake-wide, causing variable shore- line retreat ranging from tens of meters to over a kilometer (Lorang et al., 1993b, a; Lorang and Stanford, 1993). However, large differences in shoreline loss have been shown to result from small changes in lake level of $30 \mathrm{~cm}$ or less (Lorang et al., 1993a; Lorang and Stanford, 1993). Some of the variations are seasonal, while others have diurnal or hourly periods; hence water level change occurs across a range of timescales that spans 5 orders of magnitude (Morrison et al., 2005). The mode 1 seiche period along the long axis of the lake can be approximated from Eq. (1); however, actual seiche motions are influenced by bathymetry, the shape of the shoreline, and other factors. For a $50 \mathrm{~km}$ long lake with an average depth of $50 \mathrm{~m}$, the seiche will have a period of approximately $2 \mathrm{~h}$, while the cross-lake seiche will have a period of approximately $30 \mathrm{~min}$, as it would be in Polson Bay. Morrison et al. (2005), measuring at a single location in Polson Bay, observed a strong spectral peak in surface oscillations at a period of $2 \mathrm{~h}$, and a less energetic peak at a period of $35 \mathrm{~min}$.

\subsection{Circulation model, configuration of model runs}

The Princeton Ocean Model (POM; Blumberg and Mellor, 1987) was run on a curvilinear grid domain of 100 by 200 cells, approximating the bathymetry of Flathead Lake. The model was run in barotropic mode (no baroclinic density currents). Horizontal eddy viscosity was modeled by the Smagorinsky diffusivity (Smagorinsky, 1963) with a nondimensional coefficient $C=0.2$. We adopted a simple bottom stress parameterization based on the law of the wall and the thickness of the logarithmic layer dependent on the lake depth from Schimmelpfennig et al. (2012). The circulation was forced by an initial linear tilt of the lake surface of $0.5 \times 10^{-6}$, corresponding to the surface slope produced by surface wind stress of approximately $3 \times 10^{-4} \mathrm{~m}^{2} \mathrm{~s}^{-2}$, corresponding to winds of about $8-10 \mathrm{~m} \mathrm{~s}^{-1}$. Several model runs, with a duration of 4 days' model time, were performed with varying directions of the initial tilt. Comparison of the model outputs demonstrated essentially the same spectral composition of the seiche oscillations, so that only a single run with the south-north initial slope is analyzed below, roughly coinciding with the main axis of the lake.

\subsection{Harmonic analysis}

Harmonic analysis relies on a prescribed set of frequencies persisting in the analyzed signal. Therefore, it has become a state-of-the-art method in the analysis of tidal motions, where the prevailing frequencies are determined by external forcing and are fixed independently from the characteristics of the water body. Harmonic analysis is rarely, if ever, applied to seiches, as their harmonics cannot be known a priori. Being defined by the basin morphometry, the contribution of different harmonics into the total variance of surface oscillations varies spatially over the lake. Therefore, neither single 
point data nor the spectrum averaged over the lake area is representative of the entire basin. In order to uncover the frequencies set of seiche oscillations relevant to the whole lake, the following procedure was developed and applied. In order to retain only the oscillatory motions in the surface elevation time series, the mean values were removed from velocity and surface elevation records. A spectrum was taken of the freesurface oscillations at every grid point of the model domain. Then, a "maximum spectrum estimation" was constructed by superimposing the significant spectral peaks among all grid points. The significance level of the spectral peaks was defined as the upper $99 \%$ significance level for red noise signal containing the same variance as the spectrum estimation (Kirillin et al., 2008). This approach conserved the "local modes" with relatively high amplitudes but was confined to small areas, like bays or straits. In contrast, using an average spectrum over the entire lake would smooth out local modes. Frequencies with significant spectral peaks provided a basis for subsequent harmonic analysis. The procedure of the harmonic analysis followed that described in Thomson and Emery (2001); time series of velocities and water levels at every grid point were approximated with least squares by a Fourier series containing only the selected frequencies. Through this approach, the spatial distribution was established with amplitudes and phases for every mode over the lake.

For analysis of spatial structure of vector velocity fields, the distribution of the rotary coefficients, $R$, over the lake surface for each seiche mode was estimated. The rotary spectra were defined as $R=\left(S^{+}-S^{-}\right)\left(S^{+}+S^{-}\right)$, where $S^{+}$and $S^{-}$are the counterclockwise and clockwise rotary spectra of velocity vectors, respectively. The rotary spectra were calculated by taking a Fourier transform of the complex velocity vector $u+i v$, where $u$ and $v$ are the orthogonal Cartesian components of the two-dimensional velocity (see Thomson and Emery, 2001, for details), resulting in a two-sided spectral power density estimation, with a positive (rightside) range of frequencies corresponding to the counterclockwise rotation, and a negative (left-side) range of frequencies corresponding to the the clockwise rotation (Gonella, 1972; Hayashi, 1979). As such, the rotary coefficient ranges from -1 for purely clockwise rotation to +1 for counterclockwise rotation, and is 0 for unidirectional motion (see Thomson and Emery, 2001, for details).

\subsection{Measurements}

In the following analysis, we use data on underwater pressure oscillations collected during 2011-2012 at five measurement sites around the lake (points EO, SM, WB, NR, and SB in Fig. 1) and lake level data collected by the United States Geologic Service (USGS) at Polson (point PN in Fig. 1). The pressure variations at site EO were measured by onset pressure-temperature (PT) sensors taking instantaneous measures every $2 \mathrm{~min}$. Other pressure measurements were

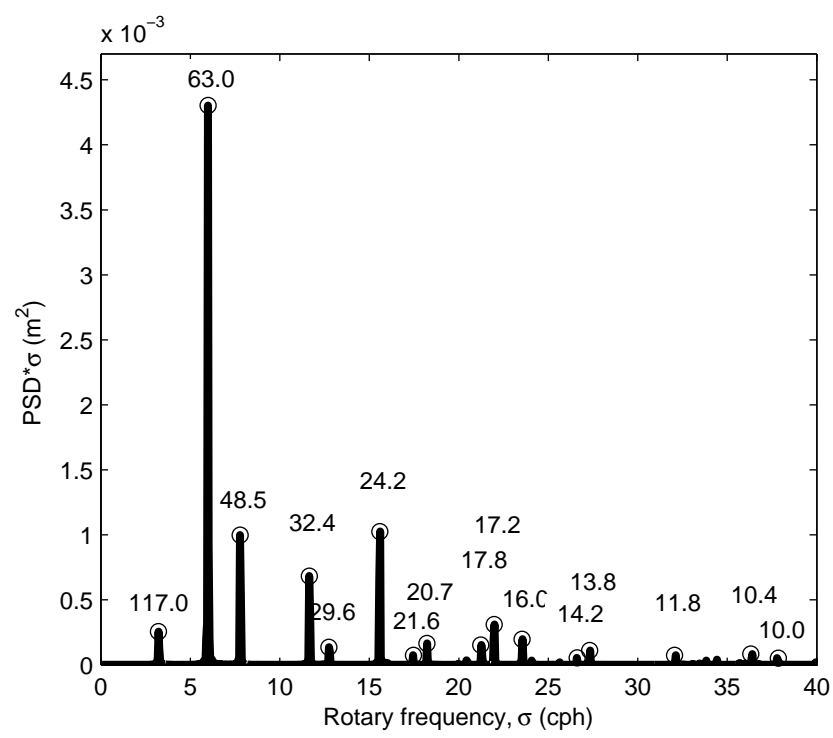

Figure 2. The synthetic maximum spectrum of modeled lake surface oscillations. Significant peaks are marked with circles with corresponding seiche periods in min.

collected with experimental PT wave recorders (msi) that sampled at $4 \mathrm{~Hz}$ and then smoothed the data and re-sampled at 2 min intervals to match the onset PT loggers. The USGS gauging station was located in a stilling well connected by a pipe to the lake, and it recorded lake level values at $1 \mathrm{~h}$ intervals.

\section{Results}

The model was driven by the initial surface slope without any additional external forcing, so that the resulting spectrum of the surface level oscillations has a line shape in contrast to continuous spectra of natural water level oscillations. The seiche frequencies and periods were therefore easily identifiable from the line spectral peaks (Fig. 2); 16 frequencies were identified, with the weakest peak containing about $1 \%$ of the spectral energy of the strongest one. The sum of spectral energies residing at the 16 frequencies contained more than $99 \%$ of the total variance (Fig. 2, Table 1).

An additional support to the results of the harmonic analysis was provided by the comparison of the time series restored from the 16 Fourier components against the original modeled time series; the restored time series captured all major features of the original variability (Fig. 3), suggesting that the 16 frequencies contain the bulk of the free barotropic motions of the lake.

For further analysis, we conditionally divided the seiche modes in three groups, based on the spatial distribution of the elevation amplitudes and phases: six "lake-wide modes" (Fig. 4), six "strong-bay modes" (Fig. 5), and four shortperiod seiche modes with the smallest amplitudes. The latter 
Table 1. Periods of free oscillation modes in Flathead Lake.

\begin{tabular}{rccr}
\hline $\begin{array}{c}\text { Significant seiche periods } \\
\text { sorted by frequency }\end{array}$ & \multicolumn{2}{c}{$\begin{array}{c}\text { Significant seiche periods } \\
\text { sorted by spectral energy }\end{array}$} \\
\hline Mode & $\begin{array}{c}\text { Period } \\
(\text { min) }\end{array}$ & $\begin{array}{r}\text { Period } \\
(\min )\end{array}$ & Mode \\
& 117.0 & 63.00 & 1 \\
1 & 63.00 & 48.48 & 2 \\
2 & 48.48 & 24.18 & 5 \\
3 & 32.40 & 32.40 & 3 \\
4 & 29.58 & 117.00 & 0 \\
5 & 24.18 & 17.16 & 9 \\
6 & 21.60 & 29.58 & 7 \\
7 & 20.70 & 20.70 & 10 \\
8 & 17.76 & 16.02 & 8 \\
9 & 17.16 & 17.76 & 6 \\
10 & 16.02 & 21.60 & 12 \\
11 & 14.20 & 13.80 & 13 \\
12 & 13.80 & 11.76 & 14 \\
13 & 11.76 & 10.38 & 11 \\
14 & 10.38 & 14.20 & 15 \\
15 & 10.00 & 10.00 & \\
\hline
\end{tabular}

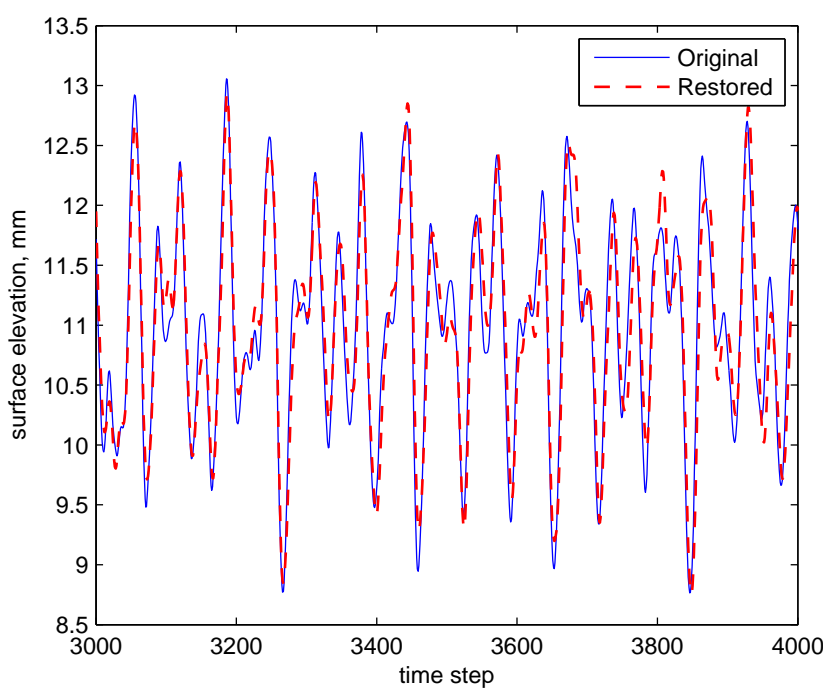

Figure 3. Lake surface oscillations at a single point in the middle of the lake produced by the model (blue solid line) and restored from the 12 harmonics (modes) of the Fourier analysis (red dashed line).

group is characterized by very small energy of oscillations and is therefore excluded from the detailed analysis below. For completeness, the spatial characteristics of the four least energetic short-period modes are provided in Fig. S1 (Supplement I).

The amount and distribution of the zero phase of the lakewide modes with periods of $63.0,32.4,21.6$, and $14.2 \mathrm{~min}$ (red lines in Fig. 4b, d-f) suggest these modes to be oneto four-node analogues of one-dimensional channel modes, respectively. Comparison of their periods to those following

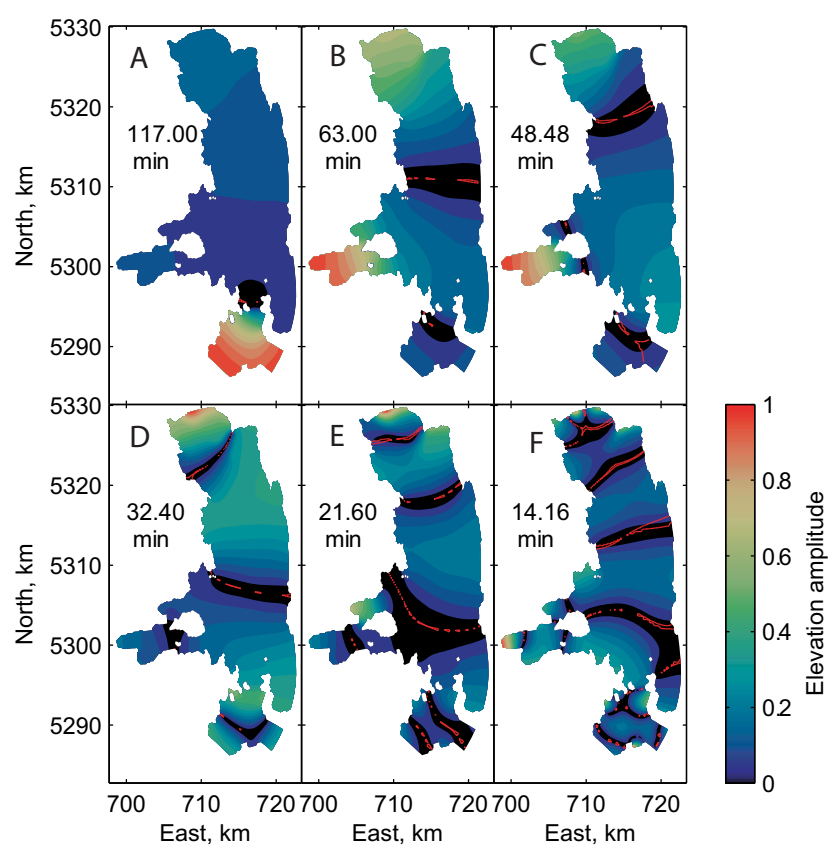

Figure 4. Relative amplitudes of the six lake-wide free oscillation modes. Zero-amplitude nodal lines are shown in red.

from the Merian formula, Eq. (1), supports this suggestion; substitution of the maximum lake length $L=44 \mathrm{~km}$ and of the mean lake depth $H=50 \mathrm{~m}$ into Eq. (1) yields similar values for the periods of the first four longitudinal modes: $66,33,22$, and $16.5 \mathrm{~min}$. Their spatial distribution is, however, modified by the irregular shape of the lake and differs significantly from that of plane longitudinal oscillations (color plots in Fig. 4; see also animated Figs. 1-4 in Supplement II). The highest water level amplitudes of the first mode (Fig. 4b) are concentrated in Big Arm Bay on the western side of the lake. These high amplitudes are apparently conditioned by a narrowing of the lake cross section towards the bay, which is separated from the main basin by two narrow straights around Wildhorse Island. Equation (1) fails to predict 117 and 48.5 min modes (Fig. $4 a-c$ ). The latter oscillation has maximum amplitudes in the Big Arm Bay on the west side of the lake, and one nodal line in the main basin of the lake. Hence, it can be associated with a one-node seiche along a shorter length scale than the maximum lake length of $44 \mathrm{~km}$, which is an analogue of a transverse seiche in a rectangular basin.

The slowest oscillation mode has a period of $117 \mathrm{~min}$, which exceeds the longest possible period of a standing wave in an enclosed basin significantly. The oscillations contain about $6 \%$ of the energy of the largest "first longitudinal" mode making it the fifth strongest oscillation mode. The oscillation has the greatest amplitudes concentrated in Polson Bay (Fig. 6). However, the amplitudes in the main basin are appreciable and take place in the counter-phase to the oscillations in Polson Bay. The zero-phase line is located in 


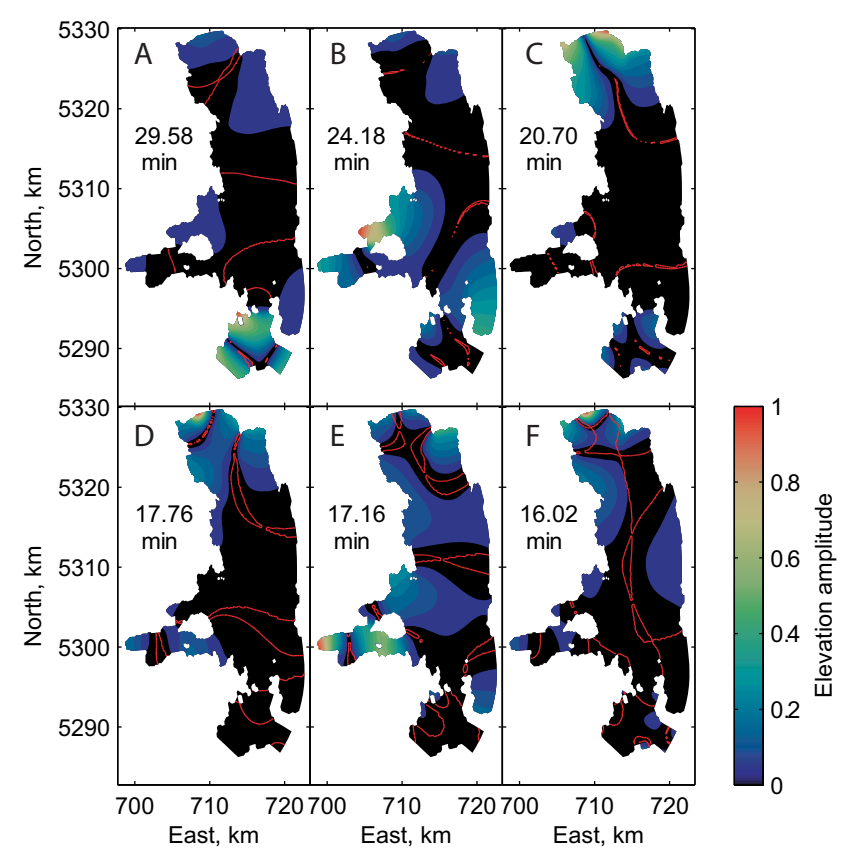

Figure 5. The same as Fig. 4 but for the six bay modes of free oscillations.

the narrow straight separating Polson Bay from the lake. These characteristics suggest the 117 min mode to be a resonant Helmholtz or "open channel" mode (Miles and Munk, 1961; Miles, 1974). In particular, this suggestion legitimizes the long period of oscillation. In an ideal case of a halfopen channel of characteristic length $L$ connected to an infinitely large basin, the Helmholtz mode has the wavelength $4 L$, which is twice the wavelength of the longest seiche in an enclosed lake. The corresponding oscillation period is also 2 times longer than the fundamental seiche, as provided by Eq. (1). The $117 \mathrm{~min}$ oscillation is indeed almost 2 times slower than that of the one-node 63 min seiche. However, in semi-enclosed basins with narrow and shallow openings, the characteristics of the Helmholtz oscillations deviate strongly from those given by idealized models (Platzman, 1972; Miles, 1974) and are determined by the width and depth of the mouth. In Flathead Lake, this role is played by the narrow straight between the main basin and Polson Bay. According to Lee (1971) and Miles and Lee (1975) the water level amplitude of the Helmholtz mode is uniform over the lake and the maximum current velocities are localized in the mouth. The ratio of the Helmholtz mode period $T$ to that of the fundamental seiche $T_{0}$ is proportional to the square root of the ratio of lake depth $H$ to the depth of the straight $h_{l}: T / T_{0}\left(H / h_{l}\right)^{1 / 2}$, i.e., the Helmholtz mode is slower than the first mode seiche. The shape of the 117 min mode in the main basin agrees well with these estimations.

Six local modes do not produce any appreciable water level oscillation in the open part of Flathead Lake (Fig. 5). Among them, the $29.6 \mathrm{~min}$ mode (Fig. 5a) is the fundamen-
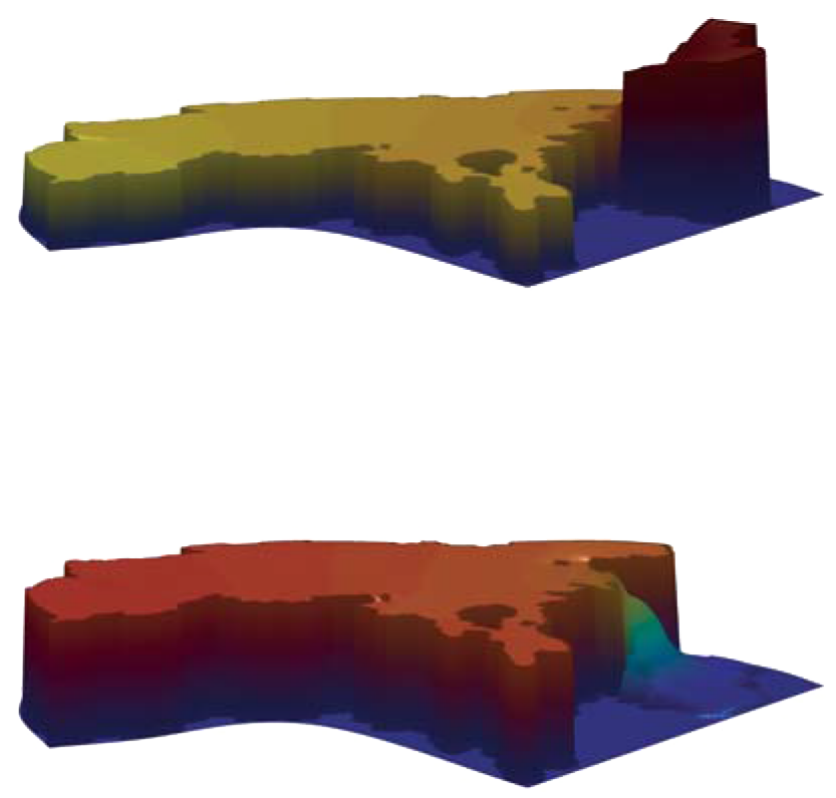

Figure 6. The shape of the lake surface corresponding to the maximum slope due to the slowest open-channel Helmholtz mode (see also animated surface oscillations in Supplement II).

tal one-node mode of the Polson Bay with a single node line and water level oscillations confined to the bay with a small response in the main lake basin. The 17.16 min mode (Fig. 5d) is an analogous oscillation in the Big Arm Bay. Both the 24.2 and 20.7 min modes have pronounced transversal components: the former in the southern and the latter in the northern part of the lake (Fig. 5b-c). This "splitting" of the transverse mode in two results from the irregular width of the lake along the main axis; the slower 24.2 min mode propagates along the widest transverse axis in the southern part of the lake. The 20.7 min mode is confined to the partially isolated northern part of the lake. The isolated morphometry of the northern basin gives rise to several local oscillation modes confined to this area (Fig. 5e and $\mathrm{f}$ and Fig. S2, Supplement I).

The distribution of the seiche current velocities is characterized by local spots of strong current intensification, confined to the shallow nearshore areas or narrow straights connecting different parts of the lake (Figs. 7 and 8). Importantly, the areas of high current velocities of many seiche modes are concentrated in the northern part of Lake Flathead, where the two major tributaries - the Flathead River and the Swan River - enter the lake. This suggests an appreciable interaction of the seiche currents with river inflows and sediment transport.

Currents produced by four seiche modes have rotational features revealed by the spatial distribution of the rotary coefficients (Fig. 8). The second longitudinal mode with a period of 48.5 min produces rotation in Polson Bay, while the transverse mode of $24.2 \mathrm{~min}$ has a single gyre in the middle part of the lake (Fig. 8a and c). Both gyres may be tentatively 


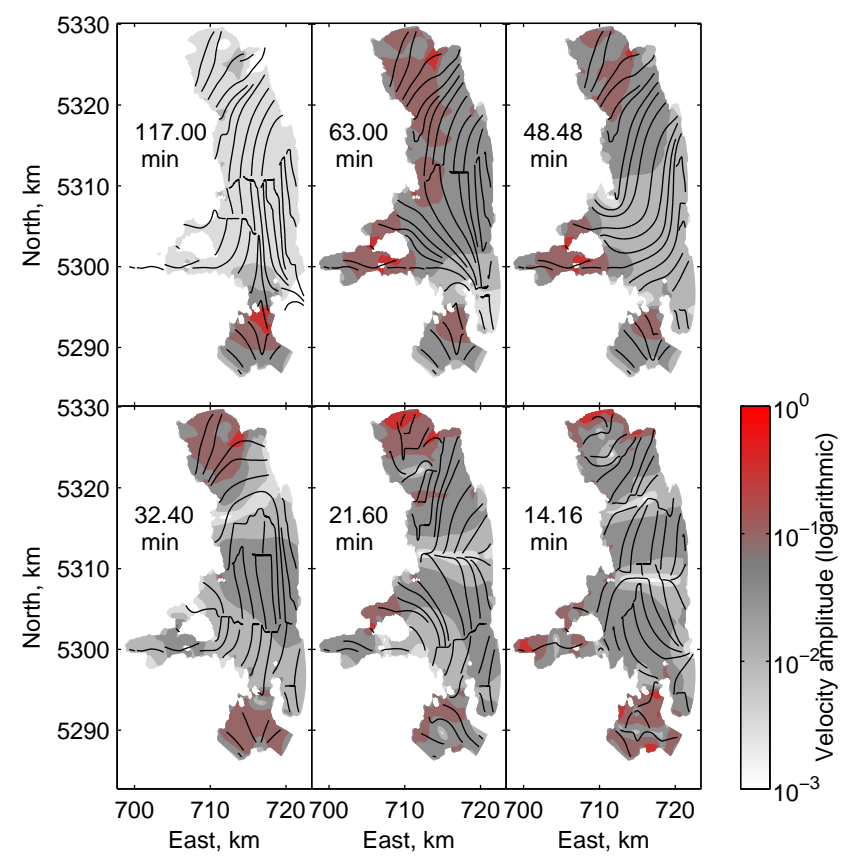

Figure 7. Normalized amplitudes of the velocity oscillations for the six modes with strong intensification of seiche currents in the nearshore areas (red color). Note the logarithmic color scale.

attributed to the effect of lateral friction at the lake shores. A more interesting pattern is revealed in oscillations with 29.6 and 20.7 min periods: both produce counter-rotating gyres in the center of the lake (Fig. 8b and d). While the direction of the rotational movement changes with the corresponding seiche frequency, the patterns suggest formation of horizontal fronts - areas of strong lateral shear - developing away from the solid boundaries. The rotary coefficients of the other seiche modes are provided in Fig. S3 (Supplement I). Among them, the most energetic long-period modes do not reveal rotational movements, while the short-period modes have a patchy pattern, which, assuming the high frequency of these modes, does not produce any appreciable long-lasting effects.

The modal structure of seiches derived from the modeling results shows good qualitative agreement with water level records from Flathead Lake (Fig. 9). The spatial structure of different seiche modes, as revealed by modeling, explains general features of the measured water level spectra variability over the lake: as predicted by the model, the $117 \mathrm{~min}$ Helmholtz mode has the strongest peak in Polson Bay and is practically absent in other locations in the lake (Fig. 9b); the first and second longitudinal modes with periods 63.0 and 48.5 min show strong peaks in the main lake basin (Fig. 9a and d); and at the measurement sites WB and NR, located close to the nodal lines of modes 1 and 2, the third mode of $32.4 \mathrm{~min}$ has a strong contribution to the oscillations (Fig. 9c and d).

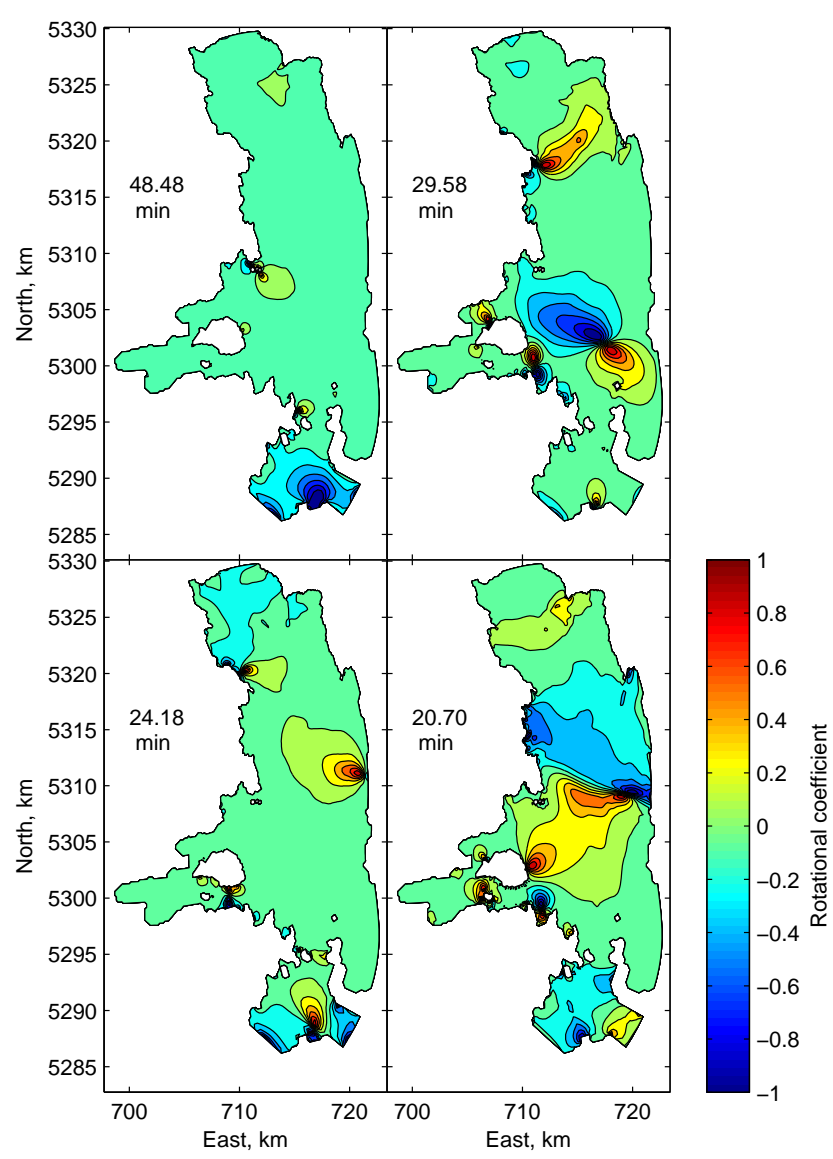

Figure 8. Rotary coefficients for the four free oscillation modes with rotational character. See Fig. S3 in Supplement I for spatial distribution of rotary coefficients for other modes.

Several important discrepancies between the modeled and observed spectra provide an insight into the features not captured by the model, but potentially significant for the hydrodynamics of Flathead Lake. The high-frequency modes with periods of $10-15 \mathrm{~min}$ are generally stronger in the observations that in the model. Observations at measurement sites WB and NR (Fig. 9c and d) show strong oscillations at periods about $10 \mathrm{~min}$, which are not pronounced on the modeled single point spectra from the closest grid points. However, these periods are found in the results of the harmonic analysis: three local modes have periods of 9.96, 10.38, and $11.76 \mathrm{~min}$; among them the $10.38 \mathrm{~min}$ mode is predicted to produce appreciable water level amplitudes in the vicinity of the measurement sites WB and NR (see Fig. S1 in Supplement I). The likely reasons for amplification of these modes are local interactions between wind and lake topography, which cannot be reproduced in the model driven by the linear initial surface slope. 


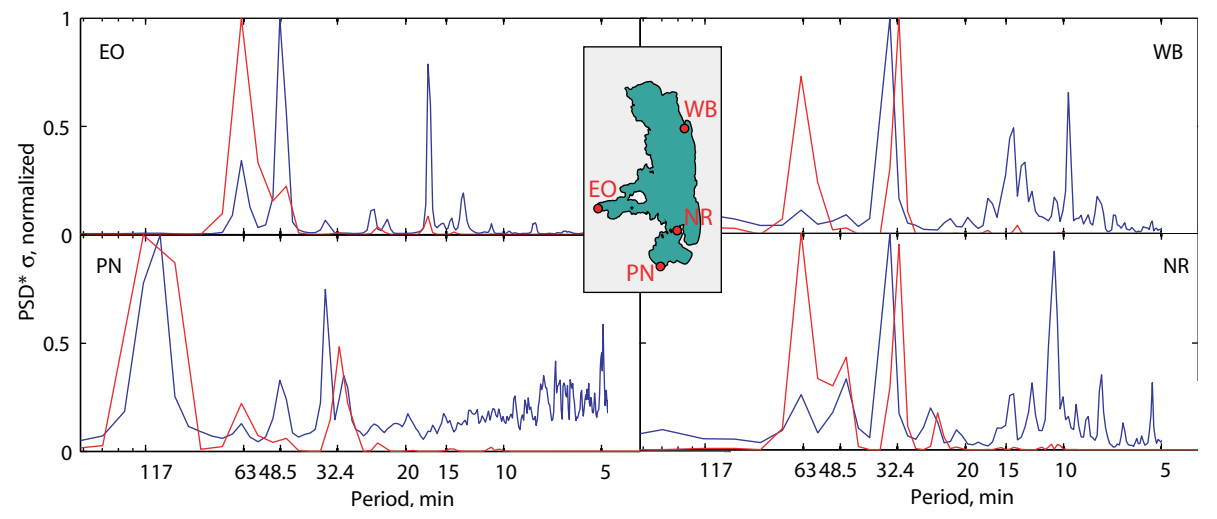

Figure 9. Spectra of measured (blue) vs. modeled (red) free-surface oscillations at four different locations in Flathead Lake. The inlet shows the positions of the corresponding measurement points.

\section{Discussion and conclusions}

Seiches in Flathead Lake have been measured in past studies (Morrison et al., 2005). However, the true complexity of their spatial variability has not been revealed with limited observational series. Our model-based approach proved to be a useful tool to assess an array of possible complex seiche motions and their rotational characteristics.

\subsection{Effectiveness of the method}

Fourier analysis is an established method for studying tidal oscillations, but is usually considered inapplicable to seiche analysis because seiche frequencies are basin-conditioned and are not known a priori. We demonstrated that isolation of the seiche frequencies by constructing a maximum spectrum over the basin under investigation is an effective way to isolate the eigenfrequencies from the output of primitive equation models, at the expense of estimation of the spectral density at each model grid point. The latter suggests $10^{3}-10^{4}$ spectrum calculations that are computationally more expensive than eigenvalue analysis (e.g., Rao and Schwab, 1976). However, modern computers make the computations approachable and the results more accurate, given that the model accurately takes into account effects on seiche motion like shoreline morphometry, basin bathymetry, Coriolis force, and bottom friction. Moreover, other effects, like variable wind forcing or variable water level, can be easily added. We used specially designed model runs with initial slope of the surface being the only driving force for the circulation, rendering isolation of the seiche frequencies straightforward. The model outputs driven by realistic forcing contain continuous spectra of motions. Significant seiche peaks can be identified by comparison of the model spectra to a background red noise spectrum containing the same integral spectral energy (Gilman et al., 1963; Bernhardt and Kirillin, 2013).
Our method allowed identification of several specific features of the basin-scale oscillations in Flathead Lake, indistinguishable by the simple channel-like approximation (Eq. 1), the most crucial being the existence of the Helmholtz mode strongly affecting the dynamics of small Polson Bay, connected to the main lake basin by a narrow straight. Another remarkable feature of the lake-wide modes revealed by the method is the deviation of their periods from those following Eq. (1). The deviation is stronger for higher modes of seiches with shorter wavelengths, which are apparently stronger affected by the irregular lake morphometry: the fourth longitudinal mode has a period of $21.6 \mathrm{~min}$ (Table 1), which is remarkably longer than the period of the fourth channel mode of $16.5 \mathrm{~min}$ (Eq. 1). Hence, a simple comparison of the oscillation periods with Eq. (1) would result in a wrong association of the fourth mode with the period of $16.02 \mathrm{~min}$; this could be a potential source of confusion when applying the channel approximation to seiche analysis.

\subsection{The role of surface seiches in the dynamics of Flathead Lake}

The essence of seiche analysis presented above consists of establishing the two-dimensional picture of seiche oscillations and designation of areas with maximum water level and current speed amplitudes. Among the applied aspects of these results are lakeshore management issues such as shoreline erosion and estimation of the flood risks. The north shore and Polson Bay are two areas of the lake that this modeling effort has shown to have both high amplitude and high current velocities associated with seiche motions. Both of these areas have experienced very high levels of shoreline retreat $\left(1-14 \mathrm{~m} \mathrm{yr}^{-1}\right.$; see Fig. S4 in Supplement I) due mainly to lake level regulation, concentrating wave energy at a single "full pool" elevation (Lorang and Stanford, 1993). Erosion processes, and hence retreat rates, are also tightly correlated to overwash events (Lorang and Stanford, 1993), which are directly related to seiche action in the lake. For marsh shore- 
lines in Polson Bay, along the north shore, and in Big Arm Bay, seiche motions control overwash and inundation patterns that ultimately control the pattern of sedimentation and subsequent vegetative colonization. Hence, seiche motions can affect shoreline erosion processes, rates of shoreline retreat, and sedimentation patterns, as well as impart a shift in the mosaic of habitat (Stanford et al., 2005) composing the riparian transition from lake to terrestrial environment.

Seiches have also caused significant flooding to shoreline development activities that have built too close to the lakeshore and at too low elevations. We found through our modeling exercise that the low-frequency Helmholtz mode had high amplitudes in Polson Bay, Big Arm Bay, and areas of the north shore. These areas would be particularly in danger of potential flooding, especially in Polson Bay, given the shorter frequencies and possibility of developing resonance conditions. High-velocity amplitudes were also found along Wildhorse Island and Polson Bay. The high-frequency modes concentrated at the north shore could affect sediment transport distribution from the river inflow as well as the drift of aquatic invasive species. Results from this study will be valuable to local planning departments and developers alike to limit future problems associated with seiche-induced flooding (Fig. S4, Supplement I) by providing maps of spatially distributed zones of expected seiche impacts.

In addition, the maps of rotational coefficients for expected dominant modes of oscillation (Fig. 8) provide valuable information about open-water mixing between gyre systems (Kirillin et al., 2008). These mixing zones are potentially important zones or "hot spots" of ecological activity from phytoplankton production to predation by zooplankton and fish. Hence, the structure and pattern of the seiche motions and associated currents and mixing patterns provide a physical template for complex food web interaction. In addition, knowing the patterns of mixing zones also provides a template or map to help guide plankton tow efforts aimed at early detection of aquatic invasive species.

\subsection{Combining observations and model efforts in seiche studies}

As discussed above, the method applied in the present study provides an effective way of gaining information on the precise seiche temporal characteristics and, more importantly, on the two-dimensional lateral distribution of the seiche amplitudes and currents. The latter are difficult to reveal from direct field observations constrained to irregular point measurements at the lake surface; however they are crucial for understanding the seiche contribution to the transport of suspended matter and lake-wide mixing. Moreover, knowledge on relative distribution of seiche intensity along the lake shores is of key importance for shoreline management. With regard to estimation of seiche effects on the littoral zone, our model effectively complements the observation data on the nearshore water level variability, as well as providing guide-

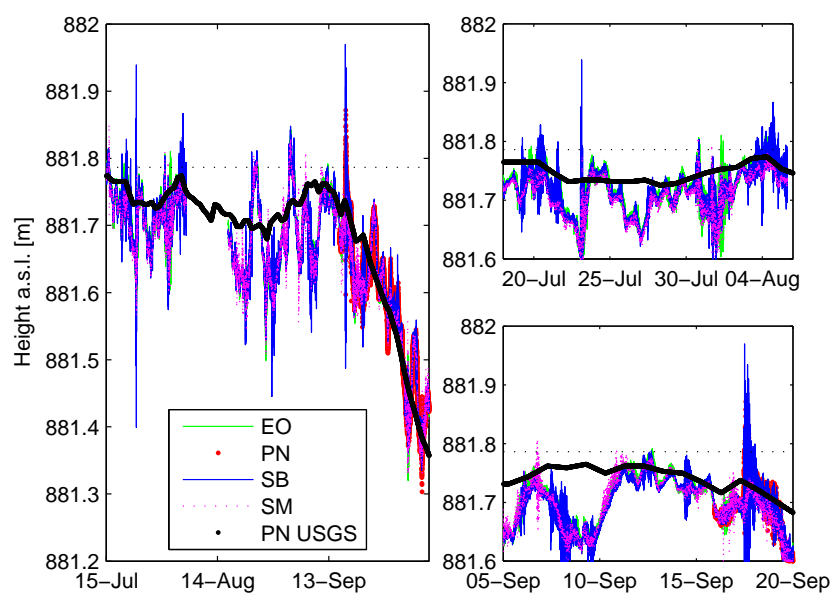

Figure 10. (a) A 3-month outtake of the lake surface oscillations in Flathead Lake. Panels (b) and (c) show a 15-day zoom of (a) for periods of strong seiche oscillations. The thick solid line is the record from the USGS gauging station in Polson Bay used for regular lake level monitoring. Thin lines are derived from the pressure records at different positions in the lake (see Fig. 1 for measurement locations). The dotted line marks the prescribed maximum regulated elevation of $881.78 \mathrm{~m}$ a.s.1.

lines for the design of water level monitoring. Our results do not include information on the absolute magnitudes of water level oscillations and currents. The latter can vary within a wide range, depending on wind forcing and wind-seiche resonance, or be produced by other disturbances, such as earthquakes (which are particularly relevant to the Flathead Lake area; Qamar et al., 1982). Variations in wind speed and direction are the major forcing factors for seiches, posing a number of relevant questions: among them, the effects of seasonal variability in wind speeds and direction over the lake on the seiche-produced lateral mixing patterns. The potential consequences of this variability for the seiche oscillations would consist in seasonally varying typical seiche amplitudes, seasonal intensification of certain seiche modes, and seiche interaction with seasonally varying drift currents. Investigation of these seiche-driven processes would be most efficient in the general context of seasonally variable transport within the lake including, along with seiches, the temporally and spatially variable wind drift and the seasonal variability of inflows and outflows. To override the inevitable deficiencies of numerical modeling approaches (such as reproduction of the bottom friction, nonlinear wave transport, and turbulence in stratified interior), model simulations should be combined in these complex investigations with spatially resolved measurements at seasonal timescales.

Wind, dam operations, and seiche oscillations in lakes can play a significant role in shoreline erosion by exposing fragile and otherwise protected backshore environments to the action of wind waves. An alteration of hydrologic connection with marsh shorelines through seiche motions ultimately im- 
pacts the mosaic of riparian habitat. Therefore, understanding food web dynamics in the lake, management of lake level regulation with dams, and the early detection of aquatic invasive species and shoreline development planning can all benefit from a more quantitative understanding of seiche motions, based on a combination of our model results and the monitoring of water level/currents.

Comparison of pressure records from transducers from different locations around the lake show distinct seiche oscillations (Fig. 10). Seiche amplitudes exceeded the regulated maximum pool elevation of $881.8 \mathrm{~m}$ by up to $15 \mathrm{~cm}$ (e.g., in Skidoo Bay; blue line in Fig. 10; see Fig. 1 for the site location). Filtered measurements by the USGS gauge used for water level regulation do not capture these oscillations. The modeling efforts in this paper indicate that this regulated level would be exceeded in other bays along the north shore, including much of the east and west shores of the north half of the lake, bays and shorelines west of Wildhorse Island, and all of Polson Bay. Hence, if lake level regulation is aimed at controlling the shoreline erosion at a lake-wide scale, then an array of real-time lake level sensors situated around the lake has to be used or the maximum elevation threshold has to be reduced by the largest seiche amplitude.

\section{The Supplement related to this article is available online at doi:10.5194/hess-19-2605-2015-supplement.}

Acknowledgements. The research was supported by the German Science Foundation (DFG projects KI 853/5-1, KI 853/7-1) and by the Leibniz Association (project SAW-2011-IGB-2). M. S. Lorang was partially supported by the FLBS Limnology Professorship endowment.

Edited by: H. H. G. Savenije

\section{References}

Bernhardt, J. and Kirillin, G.: Seasonal pattern of rotation-affected internal seiches in a small temperate lake, Limnol. Oceanogr., 58, 1344-1360, 2013.

Blumberg, A. F. and Mellor, G. L.: A description of a three-dimensional coastal ocean circulation model, in: ThreeDimensional Coastal Ocean Models, edited by: Heaps, N. S., American Geophysical Union, Washington, D.C., 1-16, doi:10.1029/CO004p0001, 1987.

Csanady, G.: Large-scale motion in the Great Lakes, J. Geophys. Res., 72, 4151-4162, 1967.

Defant, A.: Physical oceanography, Pergamon Press, New York, 1961.

Forel, F.: Le Léman: Monographie Limnologique. Tome 2: méchanique, chimie, thermique, optique, acoustique, F. Rouge, Lausanne, 1895.

Forel, F. and von Zeppelin, E.: Die Schwankungen des Bodensees, Stettner, Lindau, 1893.
Gilman, D., Fuglister, F., and Mitchell Jr., J.: On the power spectrum of "red noise", J. Atmos. Sci., 20, 182-184, 1963.

Gonella, J.: A rotary-component method for analysing meteorological and oceanographic vector time series, Deep-Sea Res. Ocean. Abstr., 19, 833-846, 1972.

Hayashi, Y.: Space-time spectral analysis of rotary vector series, J. Atmos. Sci., 36, 757-766, 1979.

Hollan, E., Rao, D., and Bäuerle, E.: Free surface oscillations in Lake Constance with an interpretation of the "Wonder of the Rising Water" at Konstanz in 1549, Arch. Meteorol. Geophys. Bioklimatol. A, 29, 301-325, 1980.

Hutter, K., Raggio, G., Bucher, C., and Salvadè, G.: The surface seiches of Lake of Zürich, Schweiz. Z. Hydrol., 44, 423-454, doi:10.1007/BF02502301, 1982.

Hutter, K., Wang, Y., and Chubarenko, I.: Physics of Lakes Vol. II - Lakes as Oscillators, Springer-Verlag, Berlin, Heidelberg, 2011.

Jönsson, B., Döös, K., Nycander, J., and Lundberg, P.: Standing waves in the Gulf of Finland and their relationship to the basinwide Baltic seiches, J. Geophys. Res.-Oceans, 113, C03004, doi:10.1029/2006JC003862, 2008.

Kirillin, G., Engelhardt, C., and Golosov, S.: A mesoscale vortex in a small stratified lake, Environ. Fluid Mech., 8, 349-366, 2008.

Kulikov, E. and Medvedev, I.: Variability of the Baltic Sea level and floods in the Gulf of Finland, Oceanology, 53, 145-151, 2013.

Lee, J.-J.: Wave-induced oscillations in harbours of arbitrary geometry, J. Fluid Mech., 45, 375-394, 1971.

Lorang, M. S.: The use of sediment analysis, sedimentary structures and water wave measurements to quantify wave energy in a shallow fresh water bay, Flathead Lake, Montana, Northw. Geol., 13, 5-14, 1984.

Lorang, M. S. and Stanford, J. A.: Variability of shoreline erosion and accretion within a beach compartment of Flathead Lake, Montana, Limnol. Oceanogr., 38, 1783-1795, 1993.

Lorang, M. S., Komar, P. D., and Stanford, J. A.: Lake level regulation and shoreline erosion on Flathead Lake, Montana: A response to the redistribution of annual wave energy, J. Coast. Res., 9, 494-508, 1993a.

Lorang, M. S., Stanford, J. A., Hauer, F. R., and Jourdonnais, J. H.: Dissipative and reflective beaches in a large lake and the physical effects of lake level regulation, Ocean Coast. Manage., 19, 263287, 1993b.

Miles, J. W.: Harbor seiching, Annu. Rev. Fluid Mech., 6, 17-33, 1974.

Miles, J. W. and Munk, W. H.: Harbor paradox, J. Waterways Harbors Div.-ASCE, 87, 111-130, 1961.

Miles, J. W. and Lee, Y.: Helmholtz resonance of harbours, J. Fluid Mech., 67, 445-464, 1975.

Morrison, A., Williams, A., and Lorang, M.: Waves and seiches in Flathead Lake, Montana: measurements of a quiet lake by differential travel-time current measurements, in: Proceedings of MTS/IEEE, IEEE OCEANS, Washington, D.C., 1421-1426, 2005.

Mortimer, C. H. and Fee, E. J.: Free surface oscillations and tides of Lakes Michigan and Superior, Philos. T. Roy. Soc. Lond. A, 281, 1-61, 1976.

Platzman, G. W.: Two-dimensional free oscillations in natural basins, J. Phys. Oceanogr., 2, 117-138, 1972. 
Qamar, A., Kogan, J., and Stickney, M. C.: Tectonics and recent seismicity near Flathead Lake, Montana, Bull. Seismol. Soc. Am., 72, 1591-1599, 1982.

Rao, D. B. and Schwab, D. J.: Two dimensional normal modes in arbitrary enclosed basins on a rotating earth: Application to Lakes Ontario and Superior, Philos. T. Roy. Soc. Lond. A, 281, 63-96, 1976.

Rudnev, S. F., Salvadè, G., Hutter, K., and Zamboni, F.: External gravity oscillations in Lake Onega, Ann. Geophys., 13, 893-906, doi:10.1007/s00585-995-0893-2, 1995.

Rueda, F. J. and Schladow, S. G.: Surface seiches in lakes of complex geometry, Limnol. Oceanogr., 47, 906-910, 2002.

Schimmelpfennig, S., Kirillin, G., Engelhardt, C., and Nützmann, G.: Effects of wind-driven circulation on river intrusion in Lake Tegel: modeling study with projection on transport of pollutants, Environ. Fluid Mech., 12, 321-339, 2012.
Smagorinsky, J.: General circulation experiments with the primitive equations: I. the basic experiment, Mon. Weather Rev., 91, 99164, 1963.

Stanford, J. A., Lorang, M. S., and Hauer, F. R.: The shifting habitat mosaic of river ecosystems, Int. Verein. Theor. Angew. Limnol. Verhand., 29, 123-136, 2005.

Suursaar, Ü., Kullas, T., and Otsmann, M.: A model study of the sea level variations in the Gulf of Riga and the Väinameri Sea, Cont. Shelf Res., 22, 2001-2019, 2002.

Thomson, R. E. and Emery, W. J.: Data analysis methods in physical oceanography, Elsevier, Amsterdam, 2001.

Turner, J.: Buoyancy effects in fluids, Cambridge Univ. Press, 1973. von der Mühll, K.: Ueber die Bewegung tropfbarer Flüssigkeiten in Gefässen. Nach Johann Rudolf Merian, Math. Annal., 27, 575$600,1886$. 